\title{
Research on the Problem of Official Rent-seeking in Public Service Outsourcing in China
}

\author{
Zhu Xiaoning ${ }^{1, a}$, Chen Wei ${ }^{2, b, *}$ \\ ${ }^{1}$ School of Public Affairs and Administration, University of Electronic Science and Technology of \\ China, Chengdu, Sichuan, China \\ ${ }^{2}$ School of Public Affairs and Administration, University of Electronic Science and Technology of \\ China, Chengdu, Sichuan, China \\ aZhuxn1956@163.com, b15828340565@163.com \\ ${ }^{*}$ Chen Wei
}

Keywords: Public service outsourcing, Official rent-seeking, Countermeasures

\begin{abstract}
As an efficient public service provision, public service outsourcing has gradually been adopted by countries all over the world. However, in the development of public service outsourcing in China, there is a corruption problem in which officials use their power for rent-seeking. This not only wastes social resources, but also reduces the quality of public service supply and harms the rights and interests of the public, which is not conducive to the long-term stability of the country. The key to solving the problem of rent-seeking by officials in public service outsourcing is to analyze the causes of the officials themselves, the symmetry of outsourcing information, the cost of rent-seeking and the supervision mechanism, and propose corresponding solutions to promote the healthy development of public service outsourcing and guarantee the quality and efficiency of public service supply.
\end{abstract}

\section{我国公共服务外包中官员寻租问题破解研究 \\ 祝小宁 $1, a$, 陈唯 $2, \mathrm{~b},{ }^{*}$ \\ 1 电子科技大学公共管理学院, 成都, 四川, 中国 \\ 2电子科技大学公共管理学院, 成都, 四川, 中国 \\ aZhuxn1956@163.com, b15828340565@163.com \\ *陈唯}

关键词：公共服务外包 官员寻租 对策建议

中文摘要. 公共服务外包作为一种高效的公共服务供给方式逐渐被世界各国所采纳, 然而在我 国公共服务外包的发展中出现了官员利用手中权力进行寻租的腐败问题，这不仅浪费了社会 资源，降低了公共服务的供给质量，更损害了公众的权利和利益，不利于国家的长治久安。 而破解公共服务外包中官员寻租的问题关键在于从官员自身、外包信息对称性、寻租成本和 监督机制四个方面分析寻租的产生原因，并提出相应的破解对策，从而促进公共服务外包的 健康发展，保障公共服务的供给质量和效率。 


\section{1.引言}

公共服务外包即政府改变公共服务由内部机构提供的传统，转而通过外部购买的方式获 得产品和服务, 其中通过市场化的竞争来提高供应商的产品和服务质量, 并对政府无力提供 公共服务的领域进行补充。 ${ }^{[1]}$ 从实质上讲, 公共服务外包就是在公共服务的供给中引入市场竞 争机制和企业管理制度，把传统的“管制统治”转变为通过签订合同的项目外包方式，将公共 服务由原来的政府的单一供给转变为企业或者是社会组织的多元供给, 这有利于提高公共服 务的供给效率，节省政府开支和优化资源的配置。

寻租即政府运用行政权力对企业和个人的经济活动进行干预和管制，妨碍市场竞争的作 用, 从而创造了少数有特权者取得超额收入的机会。[2]寻租行为的本质不是一种生产性活动, 而是对一种既得利益的再分配, 使得财富由劳动者向非劳动者转移, 而官员利用手中的权力 进行寻租, 则会损害了社会的公众利益。近年来我国查处的一系列重大腐败案件表明, 公共 服务外包领域已经成为权力寻租、腐败多发的“重灾区”和“深水区”。[3]在公共服务外包中官员 利用手中权力进行寻租会破坏市场经济中的公平竞争, 导致公共服务的供给质量下降, 损害 公众的权利和利益。因此正视公共服务外包中的官员寻租问题, 探究其产生原因和提出相关 的破解对策遏制官员权力寻租, 对于推动公共服务外包在我国的健康长久发展具有重要意义。

\section{2.我国公共服务外包中官员寻租现状}

在我国公共服务外包中，政府财政资金的提供者——纳税人将公共权力委托给政府部门 的相关机构, 再由这些机构向社会进行外包招标、竞标从而确定外包承包商, 向他们支付一 定的报酬, 从而由他们来生产一定的公共服务产品或者公共服务项目建设。美国芝加哥大学 经济学教授麦克切斯尼在分析政府设租活动时指出, 其一是政府通过对某些利益集团的政策 为诱饵, 引诱这些利益集团向他们进贡, 即政治创租; 其二是政府以制度或实践对某些利益 集团的不利、甚至有害的政策相威胁，迫使这些利益集团向他们进贡，即政治抽租。[4]

在公共服务外包过程中，外包主管部门的官员掌握了资金使用权和外包决策权，而作为 理性经济人的官员则会在追求自身利益最大化的基础上人为地设置一些信息障碍,创造一个 获取“租金”的条件，即通过设租，使得某些社会组织或企业为了获取相应的外包信息不得不 向政府官员行贿进行打听和咨询, 从而创造寻租的条件。在外包承包商的选择上, 由于外包 负责人拥有较大的决策权力, 在招标阶段可以为特定的承包商量身定做相关的外包标准和条 件, 从而创造准入壁垒, 提高其中标率; 在竞标环节, 官员可以通过暗箱操作指定相应的承 包商中标, 从而让公平竞争流于形式, 定向外包和协商外包取代了竞争性外包, 外包的竞争 性受损, 滋生权力腐败。其次, 由于公共服务外包涉及到的服务产品、项目设施等价值较大, 社会组织为了谋求自身的利益发展, 竞争比较激烈, 其中处于竞争劣势的一些供应商则会用 不正当的手段主动地贿赂相关的外包官员, 从而导致官商合谋共同寻租。这种委托人和代理 人勾结以谋取私利产生的风险都将转接到公共服务的最终承接方一一公民身上，损害公民的 权利和利益。[5]如 2010 年上海静安区的“11·15”特大火灾事故, 其成因便是负责外包的官员房 小兵利用手中的权力进行寻租, 与建设单位、投标企业、招标代理机构互相串通, 收获贿赂 62 万余元, 通过虚假招标, 违法违规、层层多次分包等形式将其外包给资质不够的供应商, 最终导致惨剧的发生。

\section{3.公共服务外包中官员寻租的产生原因}

通过我国公共服务外包官员寻租的现状可以分析出寻租问题出现的主要内部原因是官员 受利益驱使, 利用手中权力进行设租, 主动向承包商寻求租金; 外部原因则包括信息不对称 下社会组织为了谋求自身的发展主动行贿导致官员的被动寻租、相关的监督机制不完善、寻 租惩处轻, 官员的寻租成本低, 从而导致寻租现象的出现。 


\section{1 官员的经济人属性}

经济人假设即假定人思考和行为都是目标理性的, 会追求自身利益的最大化, 它是个体 行为的基本动机。传统政治学曾认为政府官员是为“公利”而存在的, 其行为目标是实现公共 利益的最大化。但是在现实中, 官员实际追求的是自身利益的最大化, 因此当寻租机会产生 时, 一旦寻租成本低于寻租收益, 其必然会利用手中的权力进行寻租。在公共服务外包的过 程中, 各级官员都有自己的私人利益, 这些不同于公共利益的私人利益便会扰乱官员的行为。 因此作为委托代理方的政府官员往往会利用手中的权力来向承包商进行人为的设租或主动与 承包商合谋寻租, 在外部监管不力的情况下尽可能寻找制度的漏洞钻空子, 从而获得超额利 润。

\section{2 信息不对称}

一方面是公共服务外包中，政府与承包商和社会公众的信息不对称。对于承包商而言， 拥有更多的信息意味着拥有更多的竞争力，因此承包商总会利用各种渠道来获取更多的信息。 与承包商相比，政府作为外包的委托代理方天然处于信息优势地位，因此，负责外包的政府 官员则会利用这个信息不对称的机会进行权力寻租。在招标阶段, 官员通过人为地隐藏信息, 不会向社会公众和承包商完全地公开外包信息，在外包内容、招标标准、以及承包商的资质 等方面人为地设置信息障碍，将这些可靠、有效的信息作为筹码作为租金进行寻租，从而实 现自身利益的最大化; 在外包项目建设中, 官员通过与承包商合谋, 故意将项目建设进程、 资金使用情况、合同变更情况等不向公众公布以隐蔽自己的寻租行为; 在外包项目的验收阶 段, 验收标准、绩效考核评估等信息公开程度不够, 并且作为委托方的公众在整个外包流程 中均处于信息劣势方, 对于外包承包商的选择、外包项目的建设进程、外包项目的建设验收 等均缺乏主动获取的意识, 为官员利用权力寻租提供了机会。另一方面, 在客观实际中我国 公共服务外包的信息发布机制不健全，缺乏完善的信息发布平台。目前我国外包的信息发布 主要是以政府在网上公布、利用媒体进行宣传等单一方式为主, 模式单一的信息公开方式也 增加了官员利用信息垄断进行权力寻租的可能性。

\section{3 监管机制不完善}

公共服务外包中有效的监督机制应该是政府内部监督和社会外部监督相结合，形成相互 交叉的监督网。但是，由于目前我国公共服务外包中的监督机制不完善，导致官员寻租的现 象时有发生。一方面，我国公共服务外包的监管机制以政府内部自上而下的监督为主，缺乏 社会第三方的外部监督，这便会出现公共服务外包中政府自己监督自己、“既当裁判员，又当 运动员”的现象, 监督的随意性导致了官员寻租行为的产生。并且现行的监督以事后监督为主, 缺乏事前和事中监督, 即监督主要集中在官员权力寻租行为产生后, 在群众的强烈反应下的 迫不得已的监督，而在外包招标竞标和项目建设验收容易产生寻租行为的事前和事中阶段的 监督却很乏力。另一方面, 公共服务外包中社会的外部监督缺乏。作为委托人的公众监督意 识不强, “官本位”思想严重, 把官员的权力神圣化, 不敢监督、不想监督, 认为监督不是自己 的事, 而是纪检部门、监察部门等监督机构的事, 与自己无关，在监督中出现“搭便车”的现 象, 导致外部监督名存实亡。

\section{4 官员寻租的低成本}

公共服务外包中官员寻租的成本表现为寻租付出的私人成本、寻租被发现的风险成本和 寻租受到处罚的惩处成本。政府作为公共服务的唯一供给主体，外包的审批权集中于政府的 某个部门或相关官员手中, 高度集中的审批权和决策权带来的结果就是寻租的便捷性, 即官 员可以轻易地利用权力进行寻租, 其不需要花费过多的时间和精力便可以轻易地利用手中的 权力和外包中的信息不对称来设置租金, 因此官员寻租的私人成本较低; 同时由于监管的缺 
乏和公众对外包信息的不了解，官员利用权力进行寻租被发现的风险成本低; 目前我国对于 寻租者的处罚大多以党内警告和行政处罚为主，惩处力度不大，官员寻租的惩处成本低。而 在公共服务外包中, 获取的收益往往能达到项目的百分之三到百分之五, 因此在低寻租成本 和寻租高收益的驱动下，作为经济人的官员必然会进行权力寻租。

\section{4.公共服务外包中官员寻租的破解对策}

公共服务外包中官员寻租问题的产生不仅包括官员自身的原因，也有信息不对称、外包 审批权力过大、寻租成本低、监督不完善等诸多外部原因。因此, 有效破解公共服务外包中 官员寻租的问题的关键在于建立完善的制度体系、加强对官员的约束和思想教育、建立完善 的外包信息发布机制和监督机制和提高官员的寻租成本从而实现公共服务的“廉洁”外包。

\section{1 弱化官员经济人行为，加强思想道德教育}

政府应该加强对各级行政主管官员和外包负责人的思想道德教育，建立深刻完整的价值 信念, 提高官员的思想道德素质。建立高素质的公务员队伍需要从公务员的人力资源建设入 手，加强对官员的宣传教育、职业道德教育和法治教育，大力推进社会主义核心价值体系的 教育学习, 加强行政伦理建设, 将公平廉洁的信念内化; 同时要营造以德行政、廉政的氛围, 建立科学的绩效考核机制和反腐倡廉的激励机制, 防止思想教育流于形式, 并且在注重思想 教育的同时加强对官员的物质激励，实现“高薪养廉”，让官员没有寻租的欲望，不想寻租。

\section{2 完善信息公开，增强信息的对称性}

公共服务廉洁外包的前提和保障就是信息的公开性。缺乏公开性、透明性和公正性的公 共服务外包不仅会损害政府的权威，更会导致公共服务的供给质量的下降，损害公众的权利 和利益。因此让权力在阳光下运作，防止官员的权力寻租，关键在于建立高效、透明的信息 公开体系。首先，在外包招标阶段，政府应该实现招标的公开性，让社会组织平等地参与外 包招标竞标。同时公开的招标内容应包括外包内容、承包商的标准、项目建设等详细信息, 保证信息的完整性和准确性; 在外包项目建设中, 应加强对外包项目的承包商选择、项目建 设流程、合同变更等信息的公开，保障公众的知情权，让外包在公众的监督中运行; 在外包 项目的验收阶段，对于项目建设的考核评估标准、合同的履行程度等也应该向社会公开，对 外包项目的有效考核评估是提供高质量的公共服务的保障。

\section{3 完善公共服务外包监督机制}

一方面要完善政府内部的监督机制。内部监督绝不意味着自己监督自己或者不监督，因 此要保障内部监督的独立性和建立监督问责机制。公共服务外包中出现官员寻租腐败的问题 不仅要追究外包负责官员的责任, 还要追求监督机构的责任。只有这样才能保障政府内部监 督的有效性, 以制度约束权力, 让权力在笼子里运行。另一方面要加强公共服务外包中的外 部监督, 引入独立的第三方监督机构。第三方监督是指独立于政府和承包商的由社会公众、 新闻媒体以及专业机构等组成的监督。第三方监督由于其独立性和专业性可以从多渠道获取 信息, 实现对外包的多方面、多渠道监督。第三方监管不仅要对承包商提供的公共服务的数 量和质量进行监管，还要对代理方政府的招标活动、合同签订以及项目实施的监管，确保公 共服务外包的程序公开性与结果有效性。

\section{4 加大惩治力度, 提高寻租成本}

任何寻租行为都是寻租者在成本一收益的基础上做出的选择，当寻租成本远低于寻租收 益时, 官员就很可能利用手中的权力进行寻租。因此, 首先要约束官员的权力, 通过立法明 确公共服务外包中决策者和执行者的权力，将高度集中的外包审批权和决策权分散到不同的 
部门, 避免权力集中带来的寻租腐败; 其次要加大对公共服务外包中官员寻租的查处力度和 提高对官员设租和寻租行为的惩处力度, 采取自由刑和财产刑并处的原则, 不管其寻租的数 额大小, 寻租情节的严重与否, 只要官员进行了寻租, 便没收其非法所得, 依法治罪并处以 经济惩罚，让官员寻租变为“高成本、低收益”的行为，从而让官员不敢寻租。

\section{5.结语}

公共服务外包让政府不再是公共服务的唯一生产者, 市场竞争机制的引入充分发挥了企 业和非营利组织的作用, 优化了公共服务的供给效率和供给质量, 促进了政府治理能力的提 升。但是我国公共服务外包在近年的发展中出现的官员寻租的腐败问题, 降低了政府的权威 以及损害了公众的权利和利益, 不利于社会的稳定。因此, 破解官员寻租的问题是我国公共 服务外包发展中一项迫在眉睫的任务, 而破解的关键就在于要加强对官员的思想道德教育、 完善外包的信息对称性、完善外包的内外监督机制和提高官员的寻租成本，只有这样才能消 除官员寻租的问题, 保障公共服务外包的健康发展, 提升公共服务的供给质量和保障公众的 利益和权利。

\section{References}

[1] OECD. Contracting Out Government Services: Best Practice Guidelines and Case[M]. OECD Publishing, 1998.25

[2] Buchanan. Toward a Theory of the Rent-Seeking society [M]. College Station: Texas A and M Press, 1980:89-98

[3] Zhou Wei, Li Hezhong. Rent-seeking and Governance in Government Public Service Contract Outsourcing[J]. Theoretical exploration,2014(06):87-91

[4] Fred SM c Chaney. Rent Extraction and Rent Creation in the Economic Theory of Regulation[J]. Journal of Legal Studies ,1987(1)

[5] Xia Zhiqiang, Su Xia, Risk Analysis of Public Service Contract Outsourcing Based on Double Rationality[J]. Journal of the Party School of the Provincial Committee of the Sichuan Provincial Party Committee. 2013(06):96-100 